\title{
Continuous intravenous infusion of remifentanil improves the experience of parturient undergoing repeated cesarean section under epidural anesthesia, a prospective, randomized study
}

\author{
Wei Yan ${ }^{1,2}$, Yun Xiong ${ }^{1}$, Yu Yao ${ }^{1}$, Feng-jiang Zhang ${ }^{1}$, Li-na Yu ${ }^{1}$ and Min Yan ${ }^{1 *}$ id
}

\begin{abstract}
Background: Unsatisfactory analgesia would occur frequently during repeated cesarean section under epidural anesthesia. The aim of this study is to observe the effects of intravenous remifentanil on maternal comfort, maternal and neonatal safety during repeated cesarean section under epidural anesthesia.

Methods: A total of 80 parturients undergoing repeated cesarean section were involved in the study. The patients were randomly divided into the intravenous remifentanil- assisted epidural group (group R) and epidural group (group E), respectively $(n=40)$. In group $R$, the remifentanil was continuously intravenously infused as an adjuvant to epidural anesthesia. In group E, $0.75 \%$ ropivacaine epidural or intravenous ketamine was administered as needed. Parturient baseline characteristics, vital signs, VAS scores, and comfort scores during surgery were recorded. Adverse effects were also recorded.

Results: A total of 80 patients were enrolled in the current study and the final analyses included 39 patients in group $R$ and 38 patients in group E. No differences in patients' baseline characteristics were found between the two groups $(p>0.05)$. Compared with group $E$, the comfort score was significantly higher in group $R(9.1 \pm 1.0$ vs. $7.5 \pm 1.3, p<0.001)$, whereas the maximum VAS score was significantly lower in group $R(1.8 \pm 1.2$ vs. $4.1 \pm 1.0$, $p<0.001)$. Maternal and neonatal adverse effects did not differ between the two groups during surgery $(p>0.05)$.

Conclusions: Continuous intravenous infusion of low-dose remifentanil can significantly improve the experience of parturients undergoing repeated cesarean section under epidural anesthesia, without noticeable maternal or neonatal adverse effects.
\end{abstract}

Trial registration: This study was pre-registered at http://www.chictr.org.cn/index.aspx (ChiCTR1800018423) on 17/09/2018. Keywords: Remifentanil, Epidural anesthesia, Repeated cesarean delivery

\footnotetext{
* Correspondence: zryanmin@zju.edu.cn

'Department of Anesthesiology, Second Affiliated Hospital, School of

Medicine, Zhejiang University, Zhejiang Province, China

Full list of author information is available at the end of the article
}

(c) The Author(s). 2019 Open Access This article is distributed under the terms of the Creative Commons Attribution 4.0 International License (http://creativecommons.org/licenses/by/4.0/), which permits unrestricted use, distribution, and reproduction in any medium, provided you give appropriate credit to the original author(s) and the source, provide a link to the Creative Commons license, and indicate if changes were made. The Creative Commons Public Domain Dedication waiver (http://creativecommons.org/publicdomain/zero/1.0/) applies to the data made available in this article, unless otherwise stated. 


\section{Background}

Epidural anesthesia is a popular and safe anesthetic technique for cesarean section $[1,2]$, which has few maternal and neonatal adverse effects, as well as excellent controllability. However, visceral pain caused by visceral traction frequently occurs in parturient with epidural anesthesia during cesarean section [3, 4]. Additionally, when the anxiety regarding surgery is included, epidural anesthesia must not be a pleasant experience for parturients.

In China, with the implementation of the following child policy, the number of parturients with a scarred uterus has dramatically increased; this event leads to an increased number of intra-abdominal adhesions [5]. Parturients with a scarred uterus may experience longer surgery duration and higher intensity of peritoneal traction, compared with uniparous women [3], which results in more serious intraoperative visceral pain during cesarean section. Propofol, thiopentone, and ketamine have been administered intravenously as rescue analgesia during cesarean section; however, these may reduce the umbilical arterial $\mathrm{pO}_{2}$ and Apgar score of neonates [6, 7].

Whilst remifentanil is an off label drug for parturients and some serious adverse effects with remifentanil have been reported previously, it has been recently said that remifentanil is effective, has less adverse effects compared to other opioid medications and is safe to use in controlled circumstances [8-10]. In our clinic, we found that continuous intravenous infusion of low-dose remifentanil has a good rescue analgesic effect on incomplete epidural analgesia and provides a degree of sedation during cesarean section, which improves the patient experience. Thus, we designed this prospective, randomized, controlled study to investigate the effects of continuous intravenous infusion of remifentanil $0.05 \mu \mathrm{g} \cdot \mathrm{kg}^{-1} \cdot \mathrm{min}^{-1}$ on parturient experience and neonatal safety among patients undergoing epidural anesthesia during repeated cesarean section.

\section{Methods}

\section{Ethics}

The study was approved by the ethics committee of Huzhou Maternity \& Child Health Care Hospital (Ethical Committee number 201801; Chairperson Pingya $\mathrm{He}$ ) and written informed consent was provided by all patients before enrollment in the study. Our study adheres to CONSORT guidelines.

\section{Study design and patient population}

A total of 80 patients with repeated cesarean section, aged 23-36 years (weight 56-90 kg, American Society of Anesthesiologists levels I and II) were involved in the study. The patients were randomly placed in either the intravenous remifentanil-assisted epidural group (group $\mathrm{R}$ ) or the epidural group (group E).

\section{Criteria for inclusion and exclusion}

Patients undergoing repeated cesarean section, with fullterm, singleton pregnancies, who had arranged for epidural anesthesia, were included in this study. Patients with contraindications for epidural anesthesia, history of allergy to bupivacaine or opioids, history of spinal surgery, or intrauterine hypoxia were excluded from this study. Patients with epidural anesthesia puncture failure, poor effect of epidural anesthesia, or intraoperative hemorrhage were also excluded from the analysis.

\section{Preoperative preparations and anesthesia protocol}

All patients fasted for $6 \mathrm{~h}$ and discontinued fluid intake $2 \mathrm{~h}$ before repeated cesarean section. Intravenous access was established, $5 \mathrm{~L} / \mathrm{min}$ oxygen was administered, and Ringer's lactate $8 \mathrm{ml} / \mathrm{kg}$ was preloaded after patients entered the operating room. Electrocardiography, noninvasive arterial pressure, respiratory rate, and pulse oximetry were routinely monitored for all parturients. RR was measured by carbon dioxide sampling.

Before epidural anesthesia was administered, patients were placed in the left lateral decubitus position. The epidural space was cannulated at the L2-3 interspace with the midline approach, using an 18-gauge Tuohy needle. A loss-of-resistance to the saline technique was used to affirm the puncture; then, a 20-gauge epidural catheter was advanced $3 \mathrm{~cm}$ cephalad. Three milliliters $1.5 \%$ lidocaine with $10 \mu \mathrm{g}$ adrenaline was injected through the epidural catheter as a test dose. Epidural administration of $0.75 \%$ ropivacaine was performed in two groups until the epidural anesthesia level of all parturients reached T6. In group $\mathrm{R}$, remifentanil was continuously intravenously infused at a rate of $0.05 \mu \mathrm{g} \cdot \mathrm{kg}^{-1} \cdot \mathrm{min}^{-1}$ at the beginning of the operation. The intravenous infusion rate of remifentanil was increased by $0.025 \mu \mathrm{g} \cdot \mathrm{kg}^{-1} \cdot \mathrm{min}^{-1}$ if patients complained of discomfort or pain, and the next rate of $0.025 \mu \mathrm{g} \cdot \mathrm{kg}^{-1} \cdot \mathrm{min}^{-1}$ would increase if the discomfort or pain was not relieved after 5 min. The maximum rate of intravenous infusion did not exceed $0.15 \mu \mathrm{g} \cdot \mathrm{kg}^{-1} \cdot \mathrm{min}^{-1}$. If excessive sedation or respiratory depression occurred, intravenous infusion of remifentanil was reduced by $0.025 \mu \mathrm{g} \cdot \mathrm{kg}^{-1} \cdot \mathrm{min}^{-1}$ until infusion was completely discontinued. In group $\mathrm{E}$, if the patients complained of discomfort or pain, $0.75 \%$ epidural ropivacaine was administered as needed. Intravenous infusion of ketamine was administered as required $(0.5 \mathrm{mg} / \mathrm{kg}$ per dose, repeated for $20 \mathrm{~min}$ if necessary) or general anesthesia was performed in both groups if the discomfort or pain were not relieved.

If the saturation of pulse oxygen $\left(\mathrm{SpO}_{2}\right)$ was $<95 \%$ or respiratory rate $(\mathrm{RR})$ was $<8$ times/min (i.e., respiratory depression was observed), the parturient was awakened, and assisted breathing was applied. If the heart rate (HR) was $<50$ beats/min, intravenous atropine $0.5 \mathrm{mg}$ was 


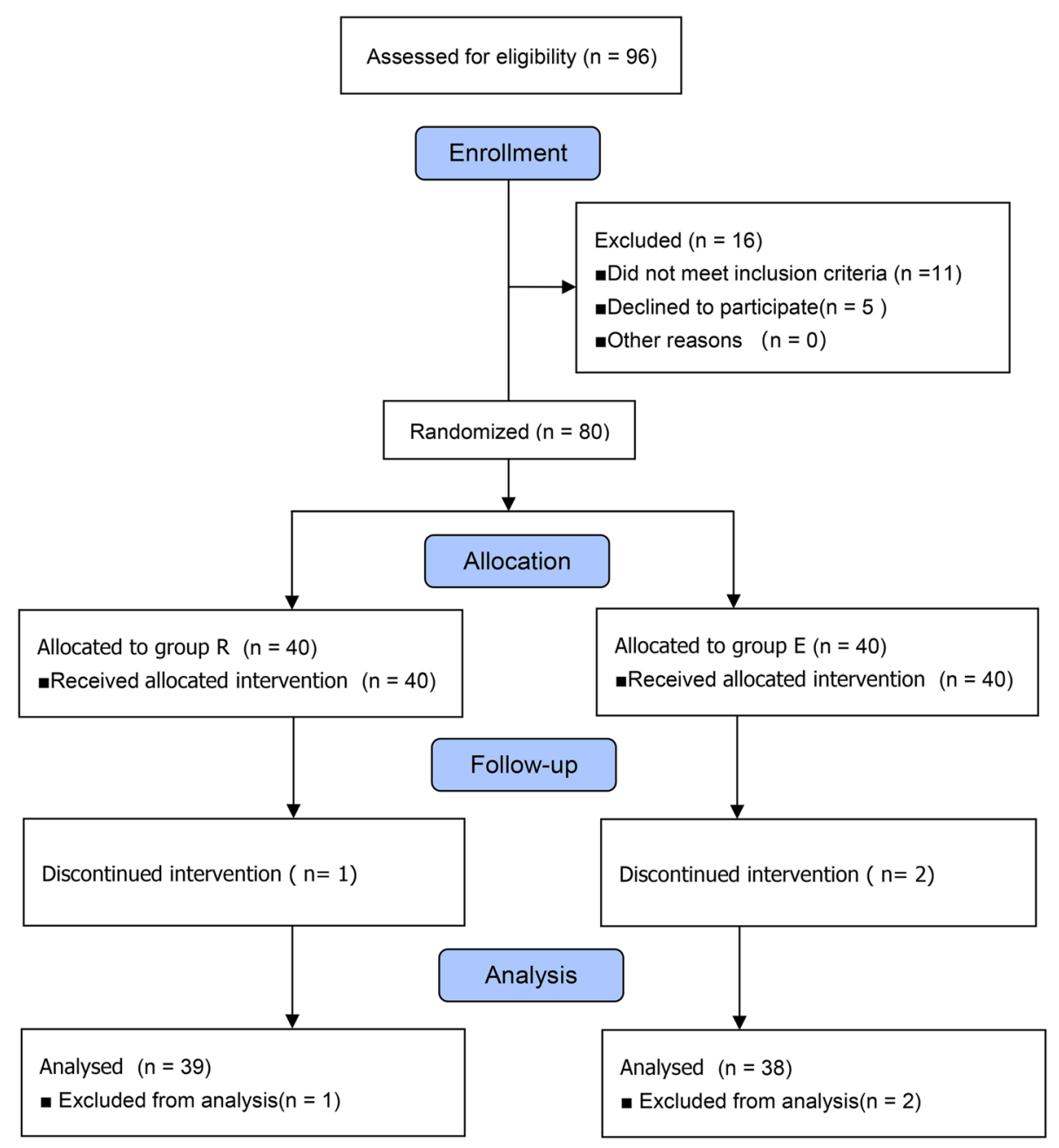

Fig. 1 Consort flow diagram

administered. If hypotension (a systolic blood pressure (SBP) reduction of $>30 \%$ or a value of $<90 \mathrm{mmHg}$ ) occurred, intravenous ephedrine 5-10 mg was administered. All anesthesia procedures were performed by the same senior anesthesiologist, and all data were recorded by an anesthesia nurse. Patients in both groups were excluded from this study if the anesthetic block level did

Table 1 Comparison of parturients' baseline characteristics

\begin{tabular}{llll}
\hline & Group R $(n=39)$ & Group E $(n=38)$ & $P$ value \\
\hline Age, years & $30.8 \pm 3.4$ & $30.3 \pm 2.6$ & 0.541 \\
$\mathrm{BMI}, \mathrm{kg} / \mathrm{m}^{2}$ & $26.7 \pm 2.2$ & $27.4 \pm 2.0$ & 0.185 \\
$\mathrm{ASA}, \mathrm{l} / \mathrm{II}$ & $37 / 2$ & $36 / 2$ & 1.000 \\
Pregnancy time, weeks & $38.9 \pm 0.8$ & $38.9 \pm 0.9$ & 0.849 \\
Surgery duration, min & $41.7 \pm 10.6$ & $46.2 \pm 13.9$ & 0.111
\end{tabular}

Data are expressed as mean \pm standard deviation, unless otherwise indicated $\mathrm{BMI}=$ body mass index, $\mathrm{ASA}=$ American Society of Anesthesiologists not reach $\mathrm{T} 10$, or if they were changed to general anesthesia $15 \mathrm{~min}$ after epidural administration.

\section{Measurements}

The following parturient data were recorded: age, body mass index (BMI), weight, ASA status, dose of ropivacaine, gestational weeks, dose of remifentanil, and epidural anesthesia block level (counted from the sacral vertebra [11]) were recorded. $\mathrm{SpO}_{2}$, mean arterial pressure (MAP), HR, and RR were recorded before anesthesia $\left(\mathrm{T}_{0}\right)$, as well as at skin incision $\left(\mathrm{T}_{1}\right)$, delivery of baby $\left(\mathrm{T}_{2}\right)$, uterine suture $\left(\mathrm{T}_{3}\right)$, and intraoperative traction $\left(\mathrm{T}_{4}\right)$ in all parturients. The visual analogue scale (VAS) score was recorded at $\mathrm{T}_{1}, \mathrm{~T}_{2}, \mathrm{~T}_{3}$, and $\mathrm{T}_{4}$; the maximum VAS score during surgery was also recorded. The level of sedation (evaluated by the Ramsay Sedation Scale) was recorded at $\mathrm{T}_{0}, \mathrm{~T}_{1}, \mathrm{~T}_{2}, \mathrm{~T}_{3}$, and $\mathrm{T}_{4}$. The degree of comfort during surgery was assessed using the numerical rating scale (NRS, $0=$ least comfort imaginable, 
Table 2 Information regarding intraoperative anesthetic drugs and oxytocin usage

\begin{tabular}{llll}
\hline & Group R $(\mathrm{n}=39)$ & Group E $(\mathrm{n}=38)$ & \\
\hline Anesthesia level, segment & & $17.2 \pm 0.5$ & 0.572 \\
Before surgery & $17.1 \pm 0.4$ & $16.1 \pm 0.5$ & 0.161 \\
At the end of the surgery & $15.9 \pm 0.4$ & $18.0 \pm 1.4$ & 0 \\
Ropivacaine dosage, $\mathrm{ml}$ & $16.8 \pm 0.4^{*}$ & & $<0.001$ \\
Remifentanil dosage, $\mu \mathrm{g}$ & $169.2 \pm 14.2$ & 4 & 0.001 \\
Ketamine, $\mathrm{n}$ & 1 & 7 & 0.340 \\
Repeat oxytocin administration, $\mathrm{n}$ & 6 & $311 \pm 109$ & 0.859 \\
Blood loss during surgery, $\mathrm{ml}$ & $308 \pm 62$ & & \\
\hline
\end{tabular}

Data are expressed as mean \pm standard deviation or $n$

"Statistically significant difference between groups according to independent-sample Student's t-tests

$10=$ very comfortable) [12]. The use of intraoperative oxytocin was recorded in both groups. Incidences of intraoperative respiratory depression $(\mathrm{RR}<8$ times/min), bradycardia, hypotension, and postoperative adverse reactions were recorded for both groups; Apgar scores were recorded at 1and $5 \mathrm{~min}$ after birth for both groups, as were the numbers of neonatal resuscitations and the $\mathrm{pH}$ value of neonatal umbilical arterial blood.

The comfort scores during surgery were the primary outcome measure of the study; the secondary outcomes were the maximum VAS score, and maternal and newborn adverse effects during surgery. In current study, another anesthesiologist was responsible for the data record.

\section{Statistical analysis}

In a preliminary trial of 20 patients, the comfort scores during surgery were $8.9 \pm 0.9$ and $7.8 \pm 1.6$ in groups $R$ and $E$, respectively. Based on the preliminary trial, 26 patients were required per group to detect a $15 \%$ increase of comfort score for $90 \%$ power and an $\alpha$ level of 0.05 , with a drop-out rate of $15 \%$. Data are expressed as mean \pm standard deviation (SD), or numbers of patients, as appropriate. Statistical analyses were performed using independent t-tests, the chi-squared test, Fisher's exact test, and repeated measures analysis of variance, as appropriate. All statistical analyses were performed using

Table 3 Comparison of Ramsay score between the two groups at $T_{0}$ to $T_{4}$

\begin{tabular}{llll}
\hline & Group R $(n=39)$ & Group $E(n=38)$ & $P$ value \\
\hline$T_{0}$ & $1.92 \pm 0.27$ & $1.89 \pm 0.31$ & 0.670 \\
$\mathrm{~T}_{1}$ & $2.18 \pm 0.39^{*}$ & $1.87 \pm 0.34$ & $<0.001$ \\
$\mathrm{~T}_{2}$ & $2.26 \pm 0.50^{*}$ & $1.84 \pm 0.37$ & $<0.001$ \\
$\mathrm{~T}_{3}$ & $2.56 \pm 0.79^{*}$ & $1.84 \pm 0.37$ & $<0.001$ \\
$\mathrm{~T}_{4}$ & $2.71 \pm 0.82^{*}$ & $1.74 \pm 0.45$ & $<0.001$ \\
\hline
\end{tabular}

Data are expressed as mean \pm standard deviation or $n$. $T_{0}$ : before anesthesia, $T_{1}$ : skin incision, $T_{2}$ : delivery of baby, $T_{3}$ :uterine suture, $T_{4}$ : intraoperative traction

*Statistically significant difference between groups according to independentsample Student's t-tests
SPSS version 22.0 (SPSS Inc., Chicago, IL, USA). $p<$ 0.05 was considered to indicate statistical significance.

\section{Results}

A total of 80 patients were enrolled in the current study, and three patients were excluded from data analysis because epidural was converted to general anesthesia. Thus, the final analyses included 39 patients in group $R$ and 38 patients in group E (Fig. 1). No differences were found in the patients' baseline characteristics between the two groups $(p>0.05)$ (Table 1$)$.

There were no differences in anesthesia spread levels before surgery and at the end of operation between the two groups (both $p>0.05$ ). Compared with group $\mathrm{R}$, the ropivacaine dosage was significantly increased in group $\mathrm{E}(p<0.001)$. The usage of remifentanil in group $\mathrm{R}$ was $169 \pm 14.2 \mu \mathrm{g}$. The numbers of patients with ketamine administration and repeat oxytocin administration did not differ between the two groups (both $p>0.05$ ) (Table 2).

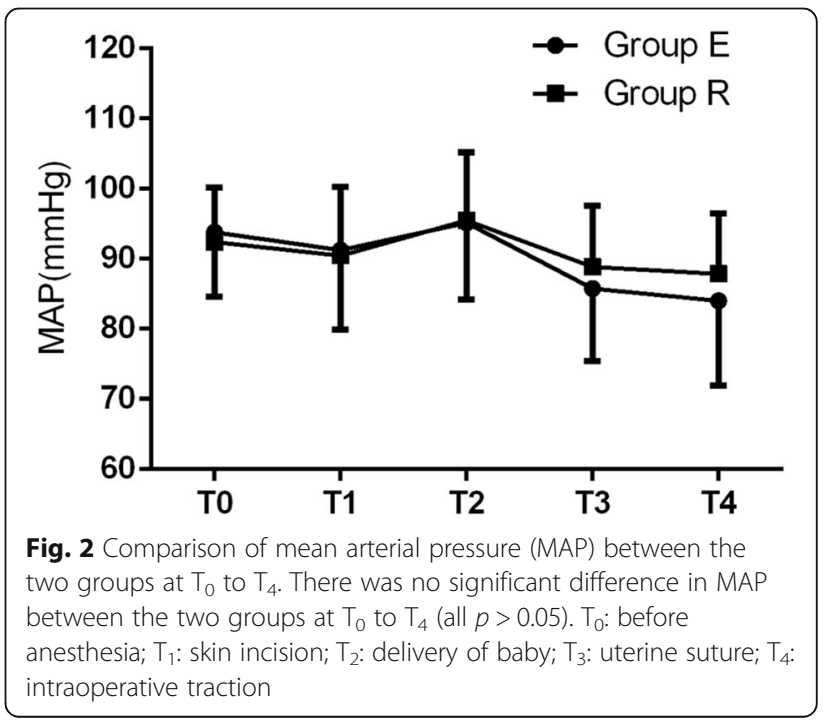




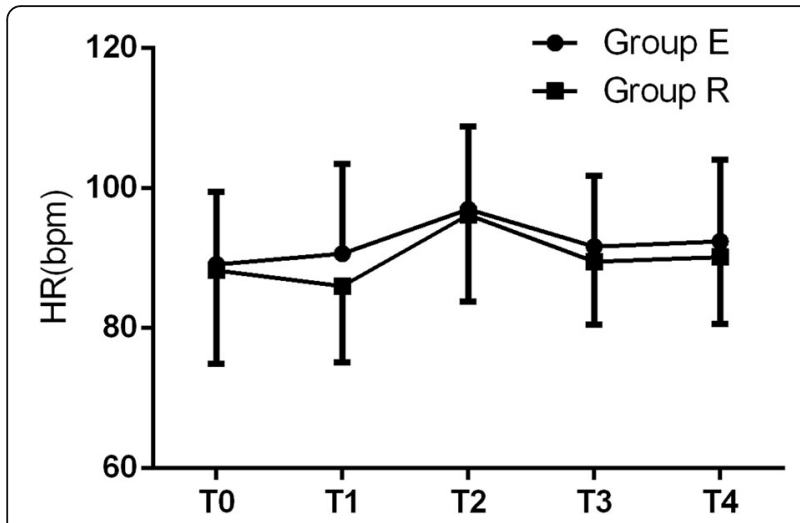

Fig. 3 Comparison of heart rate $(H R)$ between the two groups at $T_{0}$ to $T_{4}$. There was no significant difference in HR between the two groups at $T_{0}$ to $T_{4}$ (all $p>0.05$ ). $T_{0}$ : before anesthesia; $T_{1}$ : skin incision; $T_{2}$ : delivery of baby; $T_{3}$ : uterine suture; $T_{4}$ : intraoperative traction

Compared with group E, the comfort score was significantly higher in parturients in group $\mathrm{R}(9.1 \pm 1.0$ vs. $7.5 \pm 1.3, p<0.001)$, and the maximum VAS score was significantly lower in parturients in group $\mathrm{R}(1.8 \pm 1.2 \mathrm{vs}$. $4.1 \pm 1.0, p<0.001)$. Compared with group $\mathrm{E}$, the VAS score was significantly lower in group $\mathrm{R}$ at $\mathrm{T}_{1}$ to $\mathrm{T}_{4}$ (all $p<0.001)$. Compared with group $\mathrm{E}$, the incidence of VAS scores $\geq 4$ was reduced in group R (65.8\% vs. $12.8 \%$, $p<0.001)$. Compared with group $\mathrm{E}$, the Ramsay score was significantly higher at $\mathrm{T}_{1}, \mathrm{~T}_{2}, \mathrm{~T}_{3}$, and $\mathrm{T}_{4}$ in group $\mathrm{R}$ (all $p<0.001$ ) (Table 3).

There were no significant differences in MAP, HR, or $\mathrm{RR}$ between the two groups at $\mathrm{T}_{0}$ to $\mathrm{T}_{4}$ (all $p>0.05$ ) (Figs. 2, 3 and 4). Adverse reactions did not differ between the two groups during surgery (all $p>0.05$ )

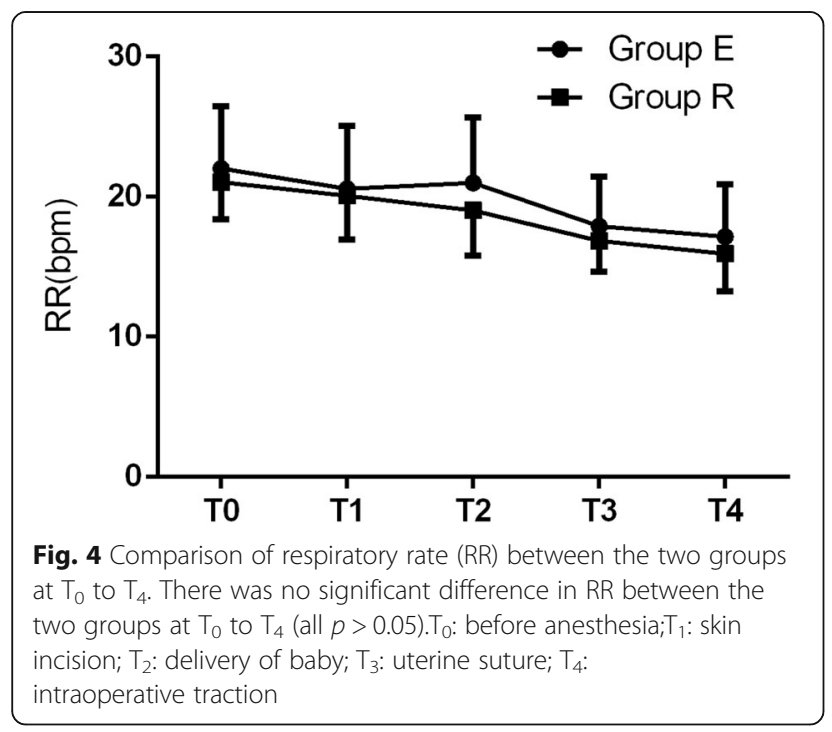

Table 4 Information regarding adverse reactions

\begin{tabular}{llll}
\hline & Group $\mathrm{R}(\mathrm{n}=39)$ & Group $\mathrm{E}(\mathrm{n}=38)$ & $P$ value \\
\hline Bradycardia, $\mathrm{n}$ & 1 & 0 & 1.000 \\
Hypotension, $\mathrm{n}$ & 0 & 4 & 0.117 \\
Respiratory depression, $\mathrm{n}$ & 2 & 0 & 0.485 \\
Nausea and vomiting, $\mathrm{n}$ & 1 & 5 & 0.191 \\
\hline
\end{tabular}

Data are expressed as $n$

(Table 4). The number of neonatal resuscitations, $\mathrm{pH}$ value of neonatal umbilical arterial blood, and Apgar scores at 1 and $5 \mathrm{~min}$ after birth were not different between the two groups (all $p>0.05$ ) (Table 5).

\section{Discussion}

The primary finding of this study was that intravenous infusion of remifentanil could significantly improve the experience of parturients undergoing epidural anesthesia during repeated cesarean section. Visceral pain was relieved during surgery without noticeable maternal or neonatal adverse effects.

In the current study, the comfort scores during surgery were designed as the primary outcome measure of the study. One end of the scores scale is marked as "the most uncomfortable", the other end is marked as "the most comfortable", and there is a scale of 0 to $10 \mathrm{~cm}$ on the back of the scale.

Previous studies have shown that the incidence rate of visceral pain ranged from 10 to $50 \%$ in parturients undergoing epidural anesthesia $[4,13]$. In the current study, approximately $65.8 \%$ parturients experienced pain (VAS scores $\geq 4$ ) during surgery without remifentanil, which was an apparent increase compared with the rate in previous studies $[4,13]$ because the subjects were undergoing repeated cesarean section. Indeed, even if the sensory block plane reaches T4, some parturients would experience some degree of visceral discomfort [14]. This maybe because visceral pain is primarily transmitted through unmyelinated $C$ fibers; although the level of sensory block in epidural anesthesia reaches T4, C fibers are not completely blocked. Opioids can inhibit $\mathrm{C}$ fibers, in addition to their central analgesic effects [15]. Thus, the

Table 5 Neonatal-related information after delivery

\begin{tabular}{llll}
\hline & $\begin{array}{l}\text { Group } \mathrm{R} \\
(\mathrm{n}=39)\end{array}$ & $\begin{array}{l}\text { Group } \mathrm{E} \\
(\mathrm{n}=38)\end{array}$ & P value \\
\hline $\begin{array}{llll}\text { Neonatal resuscitation, } \mathrm{n} \\
\text { pH value of umbilical arterial } \\
\text { blood }\end{array}$ & 2 & 2 & 1.000 \\
$\begin{array}{l}\text { Apgar score } \\
1 \text { min }\end{array}$ & & & \\
\hline min & $9.376 \pm 0.024$ & $7.380 \pm 0.023$ & 0.481 \\
\hline
\end{tabular}

Data are expressed as mean \pm standard deviation or $n$ $\mathrm{PH}=$ pondus hydrogenii 
parturient who received remifentanil experienced lower visceral pain, such that their comfort scores increased. It is worth noting that ketamine administration dose did not differ from the two groups even though the VAS was lower in parturients with remifentanil. It was because some parturients thought that it was unacceptable using ketamine during repeated cesarean section.

A previous study showed that $0.1 \mu \mathrm{g} \cdot \mathrm{kg}^{-1} \cdot \mathrm{min}^{-1} \mathrm{remi}-$ fentanil could provide effective analgesia during local anesthesia with little influence on respiration and hemodynamics in a general patient population [16]. In the current study, $0.05 \mu \mathrm{g} \cdot \mathrm{kg}^{-1} \cdot \mathrm{min}^{-1}$ remifentanil was administered; we also found that it showed little influence on respiration and hemodynamics in parturients. Although two cases of respiratory depression were found in parturients with remifentanil, it only manifested in the decline of respiratory rate. After reducing the speed of remifentanil infusion and awaken the patient, the respiratory rate returns to normal. Notably, parturients with epidural anesthesia alone may experience greater hypotension because larger doses of ropivacaine were used. Avramov et al. [16] and Kan et al. [17] reported that remifentanil could also provide a degree of sedation, which improved patient comfort levels in the current study. In obstetric surgery, it is important to determine whether administered drugs affect uterine contractions. The present study showed that intravenously administered low-dose remifentanil had a minimal effect on uterine contraction, based on the requirement for repeated usage of oxytocin and the blood loss during surgery.

Kan et al. [17] reported that remifentanil can cross the placenta, and that it appears to be rapidly metabolized, redistributed, or both, without neonatal adverse effects. Lee et al. [18] also found that remifentanil can be safely used for vaginal delivery. In the present study, as reported in previous studies, no neonatal adverse effects were observed, including changes in rates of neonatal resuscitation, the $\mathrm{pH}$ value of neonatal umbilical arterial blood, and Apgar scores. Van de Velde et al. [19] reported that a $0.50 \mu \mathrm{g} / \mathrm{kg}$ intravenous bolus of remifentanil induction dose, followed by a continuous infusion of $0.20 \mu \mathrm{g} \cdot \mathrm{kg}^{-}$ ${ }^{1} \cdot \mathrm{min}^{-1}$, caused partial neonatal depression, and required brief mask-assisted ventilation. Noskova et al. [20] reported that a bolus of $1 \mu \mathrm{g} / \mathrm{kg}$ remifentanil before induction of general anesthesia decreased Apgar scores at $1 \mathrm{~min}$ after cesarean delivery, although the clinical symptoms were short. These observations were not found in the current study, because the dosage of remifentanil injection was lower than in the prior studies $[19,20]$.

In this study, four neonates were needed resuscitation. In parturients with remifentanil, the reasons of resuscitation were umbilical cord around neck and the long delivery time of the fetus (from skin cutting to fetal delivery). In parturients without remifentanil, the reasons of resuscitation were umbilical cord around neck and amniotic fluid III degree. Although none of neonatal resuscitation was caused by remifentanil, we should consider the potential risks of using remifentanil in the clinic, decrease the dose of remifentanil and careful monitoring. Thus, low dosage of remifentanil is recommended for parturients during repeated cesarean section.

The current study has some limitations. First, previous studies have shown that epidural opioid administration may relieve visceral pain under epidural anesthesia in parturients $[3,21]$, but we did not compare the effects of intravenous remifentanil and epidural opioid on visceral pain relief. Second, only $0.05 \mu \mathrm{g} \cdot \mathrm{kg}^{-1} \cdot \mathrm{min}^{-1}$ remifentanil was used in the current study; whether this is the optimum dose requires further research. Third, neonatal resuscitation during cesarean section would occur. In order to facilitate the obstetrician to analyze the reasons for the decrease in Apgar scores, the study was not designed to be a double-blinded study, and it was hard to exclude the patients' perception, which would increase the bias.

The present study demonstrated that, in parturients undergoing repeated cesarean section, continuous intravenous infusion of low-dose remifentanil could significantly enhance the parturient experience during epidural anesthesia, without obvious maternal or neonatal adverse effects.

\section{Abbreviations}

ASA: American Society of Anesthesiologists; BMI: Body mass index; HR: Heart rate; MAP: Mean arterial pressure; RR: Respiratory rate; SBP: Systolic blood pressure; $\mathrm{SpO}_{2}$ : Saturation of pulse oxygen; VAS: Visual analogue scale

\section{Acknowledgements}

We would like to thank Qing-he Zhou for their assistance in the collection with the study. This work was supported by Huzhou Maternity \& Child Health Care Hospital.

\section{Authors' contributions}

WY has contributed to study design, patient recruitment, data collection and original draft of the manuscript writing; YX helped to conduct the study, interpret of the results and revise the manuscript for important intellectual content; YY helped to conduct the study and revise the manuscript for important intellectual content; Feng-jiang Zhang helped to conduct the study, analyze the data; LNY helped to analyze the data; MY helped to design the study and revise the manuscript. All authors read and approved the final manuscript.

\section{Funding \\ None.}

Ethics approval and consent to participate

The study was approved by the ethics committee of Huzhou Maternity \& Child Health Care Hospital (Ethical Committee number 201801; Chairperson Ping-ya He). All participants were informed about the study protocol and provided written consent to participate in the study.

Consent for publication

Not applicable.

Competing interests

The authors declare that they have no competing interests. 


\section{Author details}

'Department of Anesthesiology, Second Affiliated Hospital, School of Medicine, Zhejiang University, Zhejiang Province, China. ${ }^{2}$ Huzhou Maternity \& Child Health Care Hospital, Huzhou, Zhejiang Province, China.

Received: 10 January 2019 Accepted: 3 December 2019

Published online: 30 December 2019

\section{References}

1. Setayesh AR, Kholdebarin AR, Moghadam MS, Setayesh HR. The Trendelenburg position increases the spread and accelerates the onset of epidural anesthesia for Cesarean section. Can J Anaesth. 2001;48(9):890-3.

2. Davies SJ, Paech MJ, Welch H, Evans SF, Pavy TJ. Maternal experience during epidural or combined spinal-epidural anesthesia for cesarean section: a prospective, randomized trial. Anesth Analg. 1997:85(3):607-13.

3. Lu Q, Dong CS, Yu JM, Sun H, Sun P, Ma X, et al. The dose response of sufentanil as an adjuvant to ropivacaine in cesarean section for relief from somato-visceral pain under epidural anesthesia in parturients with scarred uterus. Medicine (Baltimore). 2018;97(38):e12404.

4. Alahuhta S, Kangas-Saarela T, Hollmén Al, Edström HH. Visceral pain during caesarean section under spinal and epidural anaesthesia with bupivacaine. Acta Anaesthesiol Scand. 1990;34(2):95-8.

5. Salim R, Kadan Y, Nachum Z, Edelstein S, Shalev E. Abdominal scar characteristics as a predictor of intra-abdominal adhesions at repeat cesarean delivery. Fertil Steril. 2008;90(6):2324-7.

6. Houthoff Khemlani K, Weibel S, Kranke P, Schreiber JU. Hypnotic agents for induction of general anesthesia in cesarean section patients: A systematic review and meta-analysis of randomized controlled trials. J Clin Anesth. 2018;48:73-80

7. Heesen M, Böhmer J, Brinck EC, Kontinen VK, Klöhr S, Rossaint R, et al. Intravenous ketamine during spinal and general anaesthesia for caesarean section: systematic review and meta-analysis. Acta Anaesthesiol Scand. 2015; 59(4):414-26.

8. Melber AA, Jelting Y, Huber M, Keller D, Dullenkopf A, Girard T, et al. Remifentanil patient-controlled analgesia in labour: six-year audit of outcome data of the RemiPCA SAFE Network (2010-2015). Int J Obstet Anesth. 2019:39:12-21.

9. MJA W, MacArthur C, Hewitt CA, Handley K, Gao F, Beeson L, et al. Intravenous remifentanil patient-controlled analgesia versus intramuscular pethidine for pain relief in labour (RESPITE): an open-label, multicentre, randomised controlled trial. Lancet. 2018;392(10148):662-72.

10. Marwah R, Hassan S, Carvalho JC, Balki M. Remifentanil versus fentanyl for intravenous patient-controlled labour analgesia: an observational study. Can J Anaesth. 2012;59(3):246-54.

11. Zhou QH, Xiao WP, Shen YY. Abdominal girth, vertebral column length, and spread of spinal anesthesia in 30 minutes after plain bupivacaine $5 \mathrm{mg} / \mathrm{mL}$. Anesth Analg. 2014;119(1):203-6.

12. Kang $\mathrm{E}$, Lee $\mathrm{KH}$, Jeon SY, et al. The timing of administration of intravenous dexmedetomidine during lower limb surgery: a randomized controlled trial. BMC Anesthesiol. 2016;16(1):116.

13. Crawford JS, Davies P, Lewis M. Some aspects of epidural block provided for elective caesarean section. Anaesthesia. 1986;41(10):1039-46.

14. Ishiyama T, Yamaguchi T, Kashimoto $\mathrm{S}$, et al. Effects of epidural fentanyl and intravenous flurbiprofen for visceral pain during cesarean section under spinal anesthesia. J Anesth. 2001;15(2):69-73.

15. Ma D, Sapsed-Byrne SM, Chakrabarti MK, Ridout D, Whitwam JG. Synergism between sevoflurane and intravenous fentanyl on $A$ delta and $C$ somatosympathetic reflexes in dogs. Anesth Analg. 1998;87(1):211-6.

16. Avramov MN, Smith I, White PF. Interactions between midazolam and remifentanil during monitored anesthesia care. Anesthesiology. 1996;85(6): 1283-9.

17. Kan RE, Hughes SC, Rosen MA, Kessin C, Preston PG, Lobo EP. Intravenous remifentanil: placental transfer, maternal and neonatal effects. Anesthesiology. 1998;88(6):1467-74.

18. Lee M, Zhu F, Moodie J, Zhang Z, Cheng D, Martin J. Remifentanil as an alternative to epidural analgesia for vaginal delivery: A meta-analysis of randomized trials. J Clin Anesth. 2017;39:57-63.

19. Van de Velde M, Teunkens A, Kuypers M, Dewinter T, Vandermeersch E. General anaesthesia with target controlled infusion of propofol for planned caesarean section: maternal and neonatal effects of a remifentanil-based technique. Int J Obstet Anesth. 2004;13(3):153-8.
20. Noskova P, Blaha J, Bakhouche H, Kubatova J, Ulrichova J, Marusicova P, et al. Neonatal effect of remifentanil in general anaesthesia for caesarean section: a randomized trial. BMC Anesthesiol. 2015;15:38.

21. Parpaglioni $R$, Baldassini $B$, Barbati $G$, Celleno D. Adding sufentanil to levobupivacaine or ropivacaine intrathecal anaesthesia affects the minimum local anaesthetic dose required. Acta Anaesthesiol Scand. 2009;53(9):121420.

\section{Publisher's Note}

Springer Nature remains neutral with regard to jurisdictional claims in published maps and institutional affiliations.
Ready to submit your research? Choose BMC and benefit from:

- fast, convenient online submission

- thorough peer review by experienced researchers in your field

- rapid publication on acceptance

- support for research data, including large and complex data types

- gold Open Access which fosters wider collaboration and increased citations

- maximum visibility for your research: over $100 \mathrm{M}$ website views per year

At $\mathrm{BMC}$, research is always in progress.

Learn more biomedcentral.com/submissions 